\title{
Are Knowledge Spillovers Driving the Convergence of Productivity among Firms?
}

\author{
By Michael K. FunG \\ Hong Kong Polytechnic University
}

Final version received 26 November 2003.

\begin{abstract}
This study evaluates the impact of knowledge spillovers on the convergence of productivity among firms. With the use of patent citation data, knowledge spillovers are decomposed into intra- and inter-industry spillovers, and internal knowledge flows. The findings from this study suggest that each firm is converging to its own steady-state productivity growth rate, which is conditional on the firm's R\&D efforts and the intensity of intra-industry spillovers it receives. Moreover, if technology followers and leaders invest equally in R\&D activities, the followers will eventually catch up with the leaders because the former tend to be the ones who receive knowledge spillovers from the latter.
\end{abstract}

\section{INTRODUCTION}

Firms improve their know-how both by producing new knowledge-innovations - and by learning from others - knowledge spillovers. It is the non-rival nature of knowledge as a productive asset that creates the possibility of knowledge spillovers, whereby investment in innovations by one party produces external benefits by facilitating innovations by other parties. Spillovers of knowledge occur when the technologies of innovators are imitated by others. Klepper and Graddy (1990) emphasize the impact of imitations on an industry's ultimate number and size distribution of firms. Jovanovic and MacDonald (1994) suggest that innovations and imitations tend to be substitutes. The benefits derived from knowledge spillovers increase with the differences in know-how, or technological gap, among firms. However, the catch-up of laggards is likely to be conditional on their absorptive capacity of knowledge spillovers. That is to say, knowledge spillovers may benefit different firms to different extents, depending on their own investment in R\&D.

Improvements in technologies give the innovators a competitive advantage, whereas spillovers of knowledge to other researchers create a business-stealing effect by lowering the cost of subsequent innovations. None the less, the 'informational barriers' that define firm boundaries have to be overcome in order to substitute knowledge spillovers for innovative efforts. According to Jovanovic and MacDonald, these barriers create lags in the adoption of technologies. An analytical model developed by Aghion et al. (1995) suggests that laggards have to go through a step-by-step process in order to adopt the technologies leaking from leaders. For instance, Nabseth and Ray (1974) and Rogers (1983) find that it may take a decade for some firms to adopt a new technology developed by others. Mansfield et al. (1981) therefore predict the spread of knowledge will tend to be gradual. ${ }^{1}$

Measures of innovative output and knowledge spillovers in this study are derived from patents and patent citations. In addition to the protection of knowledge capital, another important function performed by patents is to

(C) The London School of Economics and Political Science 2005 
facilitate knowledge spillovers by disclosing the specifications of innovations. For instance, patents facilitate information-sharing mechanisms such as patentswapping arrangements and licensing agreements among firms. In addition, the disclosure of new technologies in patents allows competitors to lower the cost of research by 'working around' past patents. (See Nadiri, 1993, for a detailed discussion.) Furthermore, a firm may benefit from its competitors' research efforts because extensive spillovers of knowledge facilitate intellectual exchanges between research teams (Spence 1984; Reinganum 1989; Cockburn and Henderson 1994), and patent citations are the 'paper trails' of these spillovers among firms. As argued by Gilbert and Newbery (1982), 'patent protection is often quite limited', and in many instances imitators could easily develop close substitutes that are not in conflict with existing patents. The computer software industry is a notable example for limited patent protection (von der Fehr 1993). The above findings from past studies suggest the patent citations are potentially a good measure for inter-firm knowledge spillovers.

Innovations and knowledge spillovers are alternative ways to make technological progress. However, technology followers have a higher incentive than the leaders to substitute knowledge spillovers for innovative effort. Therefore knowledge spillovers will result in a convergence of productivity among firms (Jovanovic and MacDonald 1994). With reference to three hightech industries-chemicals (CHEM), computers (COMP) and electrical/ electronic products (ELEC) - this study evaluates the impact of knowledge spillovers on the convergence of productivity among firms. The major hypothesis proposed in this study is as follows. The steady-state growth rate of productivity to which a firm is converging is conditional on the firm's R\&D efforts and on its absorptive capacity for receiving knowledge spillovers from other firms. In reality, a technology follower may receive spillovers of knowledge originating from either the same or other industries. For instance, a maker of computer chips may learn from its competitors about designing a new architecture; it may also imitate innovations from instrumentation in setting up an assembly line. These spillovers of knowledge from two different sources are called intra-industry and inter-industry spillovers (Fung and Chow 2002). In this study, the overall intensity of knowledge spillovers is measured by citation data in patent statistics. This measure is further decomposed into intra-industry spillovers, inter-industry spillovers and internal knowledge flows. To be more specific, intra- and inter-industry spillovers take place among firms in the same industries and across different ones; and internal knowledge flows, which occur within a firm, represent the extent to which the firm's current production of knowledge is based on its own past research. Knowledge flows of the internal type are also referred to as 'firm-specific learning', or 'self-learning'. Empirical findings from this study suggest that both R\&D efforts and intra-industry spillovers have a strong impact on the rate of productivity growth and steadystate growth rate of productivity level.

The rest of this paper is organized as follows. A few measures for knowledge spillovers are derived in Section I. In Section II total factor productivity is estimated for firms sampled from the three industries. This is followed by testing for the existence of absolute and conditional convergence of productivity among these firms in Section III. Conclusions are drawn in Section IV. 


\section{AnAtomy of KNOWledge Spillovers}

A few measures for knowledge spillovers in this study are derived from patent statistics. Economists have long used patent data to answer questions about the relationship between technological progress and such things as economic growth, market structures and productivity. The practice of measuring innovations by number of patents has been widely adopted. For instance, the intensity of forward citations has been used to measure the significance of innovations, and the flow of backward citations has been used to approximate knowledge spillovers across technological, organizational and geographical boundaries. While Griliches (1990) provides a comprehensive survey for the use of patent statistics, Lanjouw and Schankerman (1999) and Hall et al. (2000) validate the use of patents in economic research. Validating the use of patent data is beyond the scope of this study; however, I attempt to quantify different aspects of knowledge spillovers with backward citations.

Knowledge spillovers are induced benefits that an inventor receives from the innovations of others. One possible way to measure interfirm knowledge spillovers is to trace the linkage between two inventions across time as established by references or citations. Jaffe et al. (1993) and Hall et al. (2001) offer brief discussions on how patents are examined and relevant citations manifested. $^{2}$ Although these citation flows are useful when measuring knowledge spillovers, they should be used with caution. A recent survey conducted by Jaffe et al. (2000) shows that aggregate citation flows could be used as proxies for knowledge spillovers, but the 'noise' embedded in those data have to be filtered out before meaningful interpretations can be made. Another way to capture knowledge flows among firms and industries is to classify firms into different technological clusters according to the technological classifications of their patents. Jaffe (1988), for instance, relies on the US Patent and Trademark Office (USPTO) classification system to identify the proximity of firms in the technology space.

Following the work of Fung and Chow (2002), the approach employed in this study is to look at potential knowledge pools at industry level. This is equivalent to grouping firms into different technological clusters according to the types of product they produce. A similar study has been conducted by Scherer (1981) in which he constructs an 'inter-industry technology flows matrix' to examine the knowledge flows between different industries. ${ }^{3}$ In the present study, knowledge spillovers measured by backward citations are further decomposed into three separate components: intra-industry spillovers, internal knowledge flows, and inter-industry spillovers.

Intra-industry spillovers to firm $i$ in industry $j$ at time $t$ are denoted by $T R A_{i, j, t}$, which is the number of backward citations made by firm $i$ to the patents held by other firms in the same industry. ${ }^{4}$ Note that firm $i$ must belong to industry $j$ in calculating $T R A_{i, j, t}$. Thus, $T R A_{i, j, t}$ measures the intensity of knowledge flows between firms within industry $j$.

Internal knowledge flows within firm $i$ at time $t$ are denoted by $I N T_{i, j, t}$, which is the number of backward citations made by firm $i$ to the patents owned by the firm itself (so-called 'self-citations'). Internal flows could originate from the citing inventor's past research or from current research in different areas. The internal flows measured by $I N T_{i, j, t}$ can also be interpreted as 'self-learning' 
initiated by an internal knowledge base. An internal knowledge base is the stock of firm-specific knowledge accumulated in the course of research activities. A firm retrieves past experience from its knowledge base by making citations to its past patents. Therefore, the intensity of internal knowledge flows also implies a firm's ability to internalize the value of its knowledge and past experience in its future research. Innovations arising from internal knowledge flows, or 'self-learning', usually lead to the development of 'standalone' technologies.

Finally, inter-industry knowledge spillovers to firm $i$ can be derived from $T R A_{i, j, t}$ and $I N T_{i, j, t}$, which is

$$
T E R_{i, j, t}=T B C_{i, j, t}-T R A_{i, j, t}-I N T_{i, j, t},
$$

where $T B C_{i, j, t}$ is the total number of backward citations made by firm $i . T E R_{i, j, t}$ is essentially the number of backward citations made by firm $i$ to the patents held by firms outside industry $j$, which measures the spillovers to firm $i$ from sources that are external to industry $j$. These external sources could be upstream industries supplying intermediate goods to industry $j$, or industries producing totally unrelated products.

The above measures for knowledge spillovers and internal knowledge flows are constructed from patent statistics obtained from USPTO to identify those attributes in three distinct industries: the chemical, computer and electrical/ electronic industries were chosen because they are among the ones with the largest number of patents granted in the United States. The list of firms in the sample (see Fung and Chow 2002) was obtained from Hoover's Online (http:// www.hoovers.com). I compiled a unique data-set by tracing the trails of each backward citation. Some thoughts were given to striking a balance between enlisting a reasonable representation of those industries and maintaining a manageable sample size. I decided to confine my study to the following subsectors:

1. CHEM: diversified chemical products;

2. COMP: personal computers, large scale computers, data storage devices, computer software;

3. ELEC: consumer electronics, durable electrical appliances.

The sample is composed of 224 firms: 70 in CHEM, 77 in COMP and 77 in ELEC. The sampling period for the computation of $T R A_{i, j, t}, I N T_{i, j, t}$ and $T E R_{i, j, t}$ runs from 1976 to 1997. Including non-US firms in the sample is crucial because the inventors of US and of foreign origin accounted for $58 \%$ and $42 \%$, respectively, of the total patents granted in 1997. Moreover, in the same year the top 400 patenting firms alone accounted for $60 \%$ of the patents granted that year, while the patents obtained by the 224 firms in our sample is $19 \%$ of the total. ${ }^{5}$ Judging from these figures, the breadth of our sample should be large enough to generate reliable results.

Since the computation involves tracing each backward citation throughout the entire pool of patents granted to the three industries, effort is focused on the backward citations made by a subset of firms in each industry. The selection of this subset is based on the 1997 Fortune 500, which ranks firms according to their revenues. As a result, I selected 22 firms from CHEM, 24 from COMP and 18 from ELEC. To simplify the task further, I searched only 
those backward citations made within the period 1983-97. In order to compute $T R A_{i, j, t}, I N T_{i, j, t}$ and $T E R_{i, j, t}$, I screened the entire record of patents granted to industry $j$ throughout the period 1976-97 for each backward citation made by firm $i$ from 1983 to 1997 . The number of backward citations made within the period 1983-97 by the 64 selected firms was 1,229,079 (i.e. an average of 19,204 citations per firm), while the number of patents granted to the 224 firms from 1976 to 1997 was 219,703 . Note that the number of patents granted to the 64 selected firms in the same period was 144,603 , which is about $65.8 \%$ of the pooled sample. The screening and identification were processed with MATLAB.

Let $P A T_{i, j, t}$ and $R N D_{i, j, t}$ be the number of patents and R\&D expenses of firm $i$. Table 1 presents the summary statistics of $T R A_{i, j, t}, I N T_{i, j, t}$, $T E R_{i, j, t}, P A T_{i, j, t}$ and $R N D_{i, j, t}$. Figures in the table suggest that COMP has the highest level of intra-industry knowledge spillovers, ELEC the lowest, with CHEM somewhere in between. In general, the share of knowledge spillovers that is attributable to each of the three industries' R\&D activities varies from $11 \%$ to $17 \%$. A peculiar observation in the table is the large value of inter-industry knowledge spillovers, which account for over $50 \%$ of the total spillovers in each of the three industries. ${ }^{6}$

In addition, the last row of each panel in Table 1 suggests a positive correlation between the three measures of spillovers and $R \& D$ spending. If $\mathrm{R} \& \mathrm{D}$ is considered a measure of absorptive capacity, then the occurrence of knowledge spillovers may be conditional on the absorptive capacity of the

TABLE 1

Descriptive Statistics for Knowledge Spillovers, Patent Counts AND R\&D

\begin{tabular}{llllrr}
\hline & $T R A^{*}(i, j, t)$ & $I N T^{*}(i, j, t)$ & $T E R^{*}(i, j, t)$ & $P A T(i, j, t)$ & $R N D(i, j, t)$ \\
\hline CHEM & & & & & \\
Mean & 0.15 & 0.16 & 0.69 & 120.43 & 373.46 \\
St. dev. & 0.09 & 0.07 & 0.12 & 138.88 & 548.32 \\
Max. & 0.53 & 0.49 & 1.00 & 595.00 & 2594.00 \\
Min. & 0.00 & 0.00 & 0.00 & 0.00 & 0.00 \\
Correlation with R\&D & $0.637 \dagger$ & $0.544 \dagger$ & $0.609 \dagger$ & $0.811 \dagger$ & 1.000 \\
COMP & & & & & \\
Mean & 0.17 & 0.10 & 0.63 & 144.74 & 515.03 \\
St. dev. & 0.11 & 0.11 & 0.24 & 296.91 & 935.00 \\
Max. & 0.66 & 0.37 & 1.00 & 1854.00 & 5227.00 \\
Min. & 0.00 & 0.00 & 0.00 & 0.00 & 0.00 \\
Correlation with R\&D & $0.649 \dagger$ & $0.428 \dagger$ & $0.442 \dagger$ & $0.685 \dagger$ & 1.000 \\
ELEC & & & & & \\
Mean & 0.11 & 0.11 & 0.78 & 270.93 & 862.13 \\
St. dev. & 0.06 & 0.07 & 0.07 & 339.75 & 1228.42 \\
Max. & 0.21 & 0.36 & 1.00 & 1238.00 & 5522.25 \\
Min. & 0.00 & 0.00 & 0.60 & 0.00 & 0.00 \\
Correlation with R\&D & $0.744 \dagger$ & $0.389 \dagger$ & $0.657 \dagger$ & $0.848 \dagger$ & 1.000 \\
\hline
\end{tabular}

*Normalized by $T B C(i, j, t)$.

$\dagger$ Pearson correlation (significant at $5 \%$ level); TRA: intra-industry spillovers; INT: internal spillovers; TER: inter-industrial spillovers.

(C) The London School of Economics and Political Science 2005 
receiving firms. This observation is consistent with other recent studies showing that spillovers from inward foreign direct investment primarily benefit domestic companies with their own R\&D and high human capital levels (see e.g. Blomstrom 1989, 1991; Blomstrom and Sjoholm 1998; X. Liu et al. 2000; Z. Liu 2002). This issue will be explored in more detail in Section III.

\section{TOTAL FACTOR PRODUCTIVITY}

The estimation of total factor productivity (TFP) requires the estimation of a production function from which a TFP measure can be derived. The CobbDouglas production function is adopted in this study, which is expressed as follows: ${ }^{7}$

$$
Y=A K^{\alpha} L^{\beta}, \quad 0<\alpha<1 \text { and } 0<\beta<1,
$$

where, $Y$ is output (net sales), $K$ is physical capital stock, $L$ is labour input and $A$ is total factor productivity. Equation (1) allows the possibility of nonconstant returns to scale by not restricting $\alpha+\beta=1$. It has been a standard practice in past literature to divide equation (1) by $L$ to express output and physical capital on a per worker basis; that is,

$$
y=A k^{\alpha} L^{\alpha+\beta-1}
$$

where $y$ and $k$ represent output per worker and physical capital stock per worker, respectively. For the purpose of estimation, (2) is log-transformed as follows:

$$
\ln y=\ln A+\alpha \ln k+(\alpha+\beta-1) \ln L .
$$

Note that the test for constant returns to scale involves whether the coefficient of $\ln L$ equals zero. The regression equation emerges by adding a constant term and a random error to equation (3), which is stated as

$$
\ln y_{i, j, t}=D_{j}+\alpha_{j} \ln k_{i, j, t}+\left(\alpha_{j}+\beta_{j}-1\right) \ln L_{i, j, t}+\varepsilon_{i, j, t},
$$

where the subscripts $i, j$ and $t$ stand for firm $i$ in industry $j$ at time $t$, and $D_{j}$ is the constant term for industry $j$. As different industries are characterized by different capital-labour ratios and different mixes of products, the values of $D_{j}$, $\alpha_{j}$ and $\beta_{j}$ can vary across industries. By subtracting (3) from (4), we get

$$
\ln A_{i, j, t}=D_{j}+\varepsilon_{i . j . t} .
$$

Equation (5) implies that TFP is determined by an industry dummy and an error term. Hence, while two identical firms (in terms of $K, L$ and $Y$ ) within the same industry may have different levels of TFP, another two identical firms in different industries may have the same level of TFP. This difference arises from the heterogeneity of technologies and goods across industries. When using panel data, ordinary-least-squares regressions can generate misleading results if the omitted variables are time-varying. Therefore, the time-specific fixed effects are captured by adding a time trend $(t)$ in equation (4) as an additional explanatory variable. ${ }^{8}$ 
TABLE 2

Production Function Estimates (Dependent Variable $=\ln y_{i, j, t}$ )

\begin{tabular}{lccc}
\hline $\begin{array}{l}\text { Independent variable } \\
\text { (name of coefficient) }\end{array}$ & CHEM & COMP & ELEC \\
\hline Constant & $3.681^{* *}$ & $3.280^{* * *}$ & $2.579^{* * *}$ \\
& $(0.125)$ & $(0.156)$ & $(0.092)$ \\
Time & $0.039^{* * *}$ & $0.072^{* * *}$ & $0.018^{* * *}$ \\
& $(0.004)$ & $(0.007)$ & $(0.004)$ \\
$\ln k_{i, j, t}\left[\alpha_{j}\right]$ & $0.366^{* *}$ & $0.503^{* *}$ & $0.557^{* * *}$ \\
$\ln L_{i, j, t}\left[\alpha_{j}+\beta_{j}-1\right]$ & $(0.029)$ & $(0.051)$ & $(0.030)$ \\
Adj. $R^{2}$ & $-0.086^{* * *}$ & $-0.144^{* *}$ & $0.066^{* * *}$ \\
$F$ & $(0.015)$ & $(0.016)$ & $(0.012)$ \\
Durbin-Watson & 0.653 & 0.662 & 0.769 \\
& 168.071 & 134.071 & 269.028 \\
& 2.179 & 1.884 & 2.078 \\
\hline
\end{tabular}

*Values in parentheses are standard errors.

***Significant at $1 \%$ level.

Data on output (net sales), physical capital (tangible assets) and labour (number of employees) are taken from annual income statements which appear in Compustat. The sampling period runs from 1983 to 1997. The panel data-set is unbalanced because records of some firms in the early 1980s are incomplete in Compustat. Some missing observations, especially for many of the non-US firms, are supplied by information taken from the EXTEL database of financial statements. The total number of observations finally available for regression analyses is 833 (64 firms and 15 years).

Table 2 reports the estimates of equation (4) using the ordinary-leastsquares method. The estimated coefficients for all variables are significant at $1 \%$ level. The Durbin-Watson statistics, which are close to 2, lend support to the model specifications. In CHEM and COMP, the slightly negative coefficients for $\ln L_{i, j, t}$ indicate that their production functions display slightly decreasing returns to scale. ${ }^{9}$ By the same token, the same coefficient (i.e. 0.066) in ELEC implies slightly increasing returns to scale. The coefficients for $\ln k_{i, j, t}$ assign values of $0.366,0.503$ and 0.557 to the elasticity of output with respect to physical capital in CHEM, COMP and ELEC, respectively. Subtracting the coefficients of $\ln k_{i, j, t}$ from those of $\ln L_{i, j, t}$ generates the implied elasticity of output with respect to labour input of $0.548,0.353$ and 0.509 , respectively, for the three industries.

The summary statistics of the estimated TFP are presented in Table 3 . The whole sampling period is divided equally into three time blocks, and the mean, maximum and minimum of TFP for each time block are reported. The increasing mean values suggest that all the three industries experienced a positive productivity growth within the sampling period. In addition, the narrowing gap between the maximum and minimum values implies that the initially most unproductive firms grew faster than the initially most productive ones. Their respective average growth rates are $30.9 \%$ and $1.1 \%$ in CHEM, $30 \%$ and $20.1 \%$ in COMP and $13.4 \%$ and $-6.4 \%$ in ELEC. The higher growth rates for the less productive firms provide preliminary evidence for 
TABLE 3

Summary Statistics of Estimated TFP

\begin{tabular}{lcccc}
\hline Time block & Mean & Maximum & Minimum & $\begin{array}{l}\text { Standard } \\
\text { deviation }\end{array}$ \\
\hline CHEM & & & & \\
1983-87 & 3.80 & 4.75 & 2.88 & 0.331 \\
1988-92 & 3.99 & 4.62 & 3.59 & 0.226 \\
1993-97 & 4.19 & 4.80 & 3.77 & 0.202 \\
COMP & & & & \\
1983-87 & 3.42 & 4.67 & 2.40 & 0.505 \\
1988-92 & 3.69 & 4.89 & 2.69 & 0.368 \\
1993-97 & 4.06 & 5.61 & 3.12 & 0.403 \\
ELEC & & & & \\
1983-87 & 3.12 & 4.05 & 2.53 & 0.320 \\
1988-92 & 3.22 & 3.79 & 2.69 & 0.261 \\
1993-97 & 3.35 & 3.79 & 2.87 & 0.213 \\
\hline
\end{tabular}

Note: $\mathrm{TFP}=\ln A$.

convergence, which could possibly be caused by knowledge spillovers from the more productive firms to the less productive ones.

\section{TESTING FOR CONVERGENCE}

A large body of classical macroeconomic literature tests for the convergence of real income per capita among countries, beginning with Baumol (1986) and extending through Barro (1991), Mankiw et al. (1992) and Barro and Sala-iMartin (1995). Following the ideas of the above studies, I have made use of two major concepts of convergence: $\beta$-convergence and $\sigma$-convergence. Convergence of the $\beta$-type considers whether the growth of a firm's TFP exhibits a negative correlation with its current level of TFP. In other words, absolute $\beta$-convergence implies that firms with a lower TFP possess faster growth rates than firms with a higher TFP. Convergence of the $\sigma$-type considers whether the dispersion of TFP among firms diminishes over time. That is, $\sigma$-convergence implies that the distribution of TFP across firms gets tighter over time, thereby reducing some measure of dispersion. Sala-i-Martin (1996) shows that a necessary condition for the existence of $\sigma$-convergence is the existence of $\beta$-convergence. Although $\beta$-convergence is the focus of this study, the coefficient for $\beta$-convergence could be simply the result of measurement error and random shocks instead of real convergence, which is so-called 'regression towards the mean' (see Friedman 1992; Quah 1993). Therefore, for $\beta$-convergence to measure real convergence, it has to coincide with $\sigma$-convergence. Tests for $\sigma$-convergence consider the movements of a measure of dispersion, such as standard deviation. As shown in Table 3 and Figure 1, $\sigma$-convergence is clearly evidenced by the declining trend of standard deviations in TFP. As such, the results from $\beta$-convergence tests are warranted.

Existing tests for $\beta$-convergence regress an output measure on its lagged values to test for absolute convergence and on its lagged values and other 

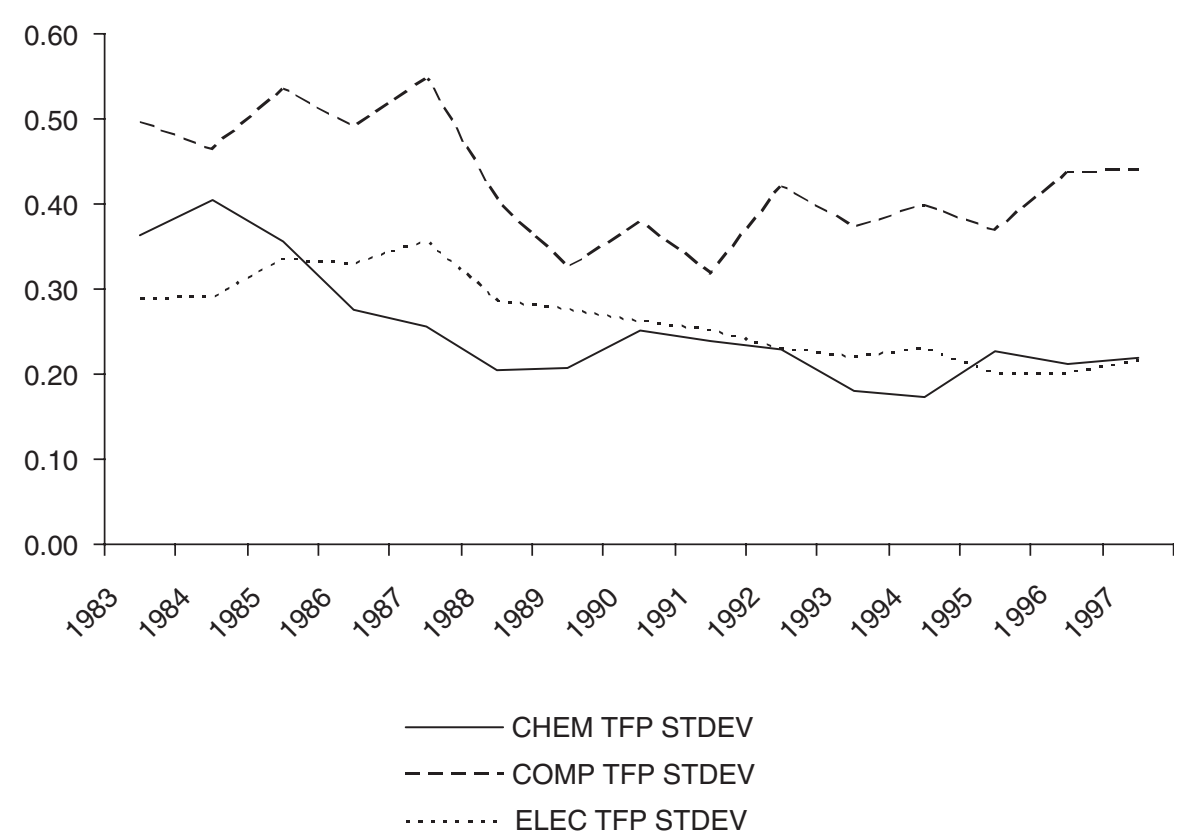

FIGURE 1. Standard deviations of TFP.

Note: $\mathrm{TFP}=\ln A$.

'conditioning variables' (i.e. some firm-specific characteristics) to test for conditional convergence. In the context of this study, absolute convergence means that all firms operating in the same industry move towards the same steady-state TFP growth rate, whereas conditional convergence means that each firm possesses its own steady-state TFP growth rate to which it is converging. The major hypothesis in this study is that the steady-state TFP growth rate of each firm is conditional on its $R \& D$ efforts as well as on its absorptive capacity to receive knowledge spillovers from other firms. Absolute convergence relies on the assumption that the only difference between firms lies in their initial TFP, which can be eliminated over time if technologies are public goods that can speedily transit across firms' boundaries through knowledge spillovers. However, if we suppose that technologies really are public goods and that all firms are facing the same potential knowledge pool for spillovers, they could still converge to different steady states if they had different absorptive capacities for receiving knowledge spillovers. Such differences in absorptive capacity among firms could arise from differences in product mixes, technological capabilities and other behavioural characteristics, such as managerial incentives. Therefore, conditional convergence predicts a positive relationship between the TFP growth rate of a firm and the distance that separates the firm from its own steady state.

Conditional convergence implies that firms with the same level of R\&D investment can grow at the same rate in the steady state. However, technological progress in real life is not an easily predictable linear process. It would therefore be interesting to know whether the productivity leaders were able to maintain their lead throughout the period of study. 
TABLE 4

Changes in TFP-Leadership Position, 1983-1997

\begin{tabular}{lccc}
\hline & CHEM & COMP & ELEC \\
\hline$P_{1}$ & 2 & 3 & 0 \\
$P_{2}$ & 6 & 11 & 5 \\
$P_{3}$ & 8 & 9 \\
$P_{4}$ & 9 & 9 & 11 \\
$P_{5}$ & 9 & 11 & 6 \\
$P_{6}$ & 10 & 9 & 9 \\
$P_{7}$ & 11 & 10 & 9 \\
$P_{8}$ & 10 & 9 & 8 \\
$P_{9}$ & 12 & 12 & 10 \\
$P_{10}$ & 9 & 11 & 11 \\
\hline
\end{tabular}

Note: $P_{i}$ is the number of times that the $i$ th leadership position changed from one firm to another.

Let $L_{1 t}$ be the identity of the top productivity leader (or the first-place leadership position in terms of TFP) at time $t$; then

$$
\rho_{1 t}=\left\{\begin{array}{lll}
0 & \text { if } \quad L_{1 t}=L_{1, t-1} \\
1 & \text { if } \quad L_{1 t} \neq L_{1, t-1}
\end{array} \text { for } t=1983, \ldots, 1997\right.
$$

In other words, $\rho_{1 t}=1$ if the firm in the first-place leadership position at time $t-1$ is replaced by another firm at time $t$; otherwise $\rho_{1 t}=0 . \rho_{i t}$ for $i=2, \ldots, n$ are defined similarly. The number of times that the $i$ th leadership position changes from one firm to another throughout the sampling period is defined as $P_{i}=\sum_{1983}^{1997} \rho_{i t}$.

The results for the first ten leadership positions are provided in Table 4. The table suggests that high-ranking leadership positions are more stable than low-ranking ones. This pattern of $P_{i}$ implies that the 'catching-up leaders' grow at different rates depending on their own R\&D intensities, and that the TFP growth rates will become more stable when the firms move closer to the steady state.

For the purposes of this study, the $\beta$-convergence of TFP among firms is tested in two ways: a cross-section test for absolute convergence, and a pooled cross-section, time series test for conditional convergence. First, the regression equation for absolute convergence has the following form:

$$
g_{i, j}^{A}=\ln \tilde{A}_{i, j}-\ln \bar{A}_{i, j}=\gamma_{j}+\lambda_{j} \ln \bar{A}_{i, j}+\varepsilon_{i, j}^{A},
$$

$$
\bar{A}_{i, j}=\sum_{t=1}^{s} A_{i, j, t} / s, \quad \tilde{A}_{i, j}=\sum_{t=s+u+1}^{15} A_{i, j, t} /(15-s-u),
$$

where $g_{i, j}^{A}$ is the TFP growth accomplished by firm $i$ between the initial and final periods, $t=1, \ldots, 15$ represents the 15 years from 1983 to 1997 . The time period from $t=1$ to $t=s$ is defined as the initial period, and that from $t=s+u+1$ to $t=15$ is the final period. $u=15-2 s$ is the time lag between the initial and final periods. $\bar{A}_{i, j}$ and $\tilde{A}_{i, j}$ are firm $i$ 's average levels of TFP in the initial and final periods, respectively. Note that $1 \leqslant s \leqslant 7$ and $13 \geqslant u \geqslant 1$. 
Equation (6) tests for absolute convergence by examining whether the TFP growth achieved in the final period is negatively related to the initial period's level of TFP. Absolute $\beta$-convergence implies $\lambda_{j}<0$.

Second, the regression equation for conditional convergence has the following form.

$$
\begin{aligned}
g_{i, j, t}^{A}= & \ln A_{i, j, t}-\ln A_{i, j, t-1}=\phi_{j}+\varphi_{j} \ln A_{i, j, t-1}+\rho_{j} \ln R N D_{i, j, t-1} \\
& +\pi_{1 j} \ln T R A_{i, j, t-1}+\pi_{2 j} \ln I N T_{i, j, t-1}+\pi_{3 j} \ln T E R_{i, j, t-1}+\mu_{i, j, t}^{A},
\end{aligned}
$$

where $R N D_{i, j, t-1}$ is $\mathrm{R} \& \mathrm{D}$ expenses taken from Compustat, a common measure for innovativeness. In (7), $R N D_{i, j, t-1}, T R A_{i, j, t-1}, I N T_{i, j, t-1}$ and $T E R_{i, j, t-1}$ are the conditioning variables that hold constant the steady-state growth rate of TFP for firm $i$. Conditional $\beta$-convergence implies $\varphi_{j}<0$. The steady-state TFP growth rate of a firm is hypothesized to be positively related to the firm's R\&D efforts and the intensity of knowledge spillovers it receives from all possible sources.

The results of the absolute $\beta$-convergence tests appear in Table 5. To allow for different time lags between the initial and final periods, equation (6) is estimated for $u=1,3$ and 5. The estimated coefficients for $\lambda_{j}$ suggest only weak evidence for absolute convergence for the pooled sample or for the two sub-samples of COMP and ELEC. Evidence exists of absolute convergence at the $5 \%$ level of significance for the sub-sample of CHEM only when $u=5$. Two findings with regard to the results of estimation deserve mention.

First, the significant coefficient for CHEM, together with the marginally significant coefficient (at 10\% level) for ELEC, when $u=5$ imply that absolute convergence is more likely to occur over a longer time period (i.e. when a longer time lag between the initial and final periods is allowed). Second, the non-existence of strong evidence for absolute convergence could be attributable to the diversity of product categories carried by the firms in the sample. As the technological characteristics of firms producing different mixes of products tend to be different, a common steady-state growth rate of TFP among them is unlikely to exist.

TABLE 5

Cross-section Tests for Absolute Convergence of TFP (DePendent VARIABLE $=g_{i, j}^{A}$ )

\begin{tabular}{lcccr}
\hline & Pooled sample & CHEM & COMP & ELEC \\
\hline$\lambda_{j}, u=1$ & -0.413 & -1.158 & 0.099 & -1.314 \\
& $(0.405)$ & $(1.041)$ & $(0.374)$ & $(1.184)$ \\
$\lambda_{j}, u=3$ & -0.442 & $-1.202 \dagger$ & 0.076 & -1.285 \\
& $(0.369)$ & $(0.878)$ & $(0.352)$ & $(1.013)$ \\
$\lambda_{j}, u=5$ & $-0.536 \dagger$ & $-1.157^{*}$ & -0.103 & $-1.226 \dagger$ \\
& $(0.384)$ & $(0.668)$ & $(0.333)$ & $(0.795)$ \\
\hline
\end{tabular}

Notes: Industry dummies are included in the pooled data set; values in parentheses are standard errors.

*Significant at $5 \%$ level; ** significant at $1 \%$ level; $†$ significant at $10 \%$ level.

(C) The London School of Economics and Political Science 2005 
A very different story emerges from the results of the conditional convergence tests reported in Table 6. Model 1 as specified in the table tests for the existence of convergence conditional on R\&D efforts. Conditional convergence in each of the three industries is evidenced by the negative and strongly significant coefficient for $\ln A_{i, j, t-1}$. This negative coefficient implies that the TFP growth rate of a firm decreases with its current level of TFP. In other words, each firm is converging to a steady-state equilibrium. Moreover, the positive coefficient for $\ln R N D_{i, j, t-1}$ suggests a positive relationship between a firm's TFP growth rate and its R\&D efforts. Hence firms investing more in R\&D activities tend to grow faster at each particular point of time and to end up with a higher steady-state TFP growth rate. The estimated coefficient generated from the pooled sample states that every $1 \%$ increase in R\&D expenses would send the growth rate of TFP higher by $0.73 \%$. The impact of

TABLE 6

Pooled Cross-section, Time Series Tests for Conditional Convergence of TFP $\left(\right.$ DePendent VARIABLE $\left.=g_{i, j, t}^{A}\right)$

\begin{tabular}{|c|c|c|c|c|}
\hline $\begin{array}{l}\text { Independent variable } \\
\text { [name of coefficient] }\end{array}$ & $\begin{array}{l}\text { Pooled } \\
\text { sample }\end{array}$ & CHEM & COMP & ELEC \\
\hline \multicolumn{5}{|c|}{ Model 1: Regression without knowledge spillovers } \\
\hline $\ln A_{i, j, t-1}\left[\varphi_{j}\right]$ & $\begin{array}{c}-0.115^{* * *} \\
(0.026)\end{array}$ & $\begin{array}{c}-0.081^{* * *} \\
(0.021)\end{array}$ & $\begin{array}{c}-0.133^{* *} \\
(0.048)\end{array}$ & $\begin{array}{c}-0.081^{* *} \\
(0.022)\end{array}$ \\
\hline $\ln R N D_{i, j, t-1}\left[\rho_{j}\right]$ & $\begin{array}{l}0.0073^{* * *} \\
(0.000)\end{array}$ & $\begin{array}{l}0.0087^{* *} \\
(0.000)\end{array}$ & $\begin{array}{l}0.0157^{\text {*** }} \\
(0.006)\end{array}$ & $\begin{array}{c}0.0053^{*} \\
(0.003)\end{array}$ \\
\hline \multicolumn{5}{|c|}{ Model 2: Regression with knowledge spillovers } \\
\hline $\ln A_{i, j, t-1}\left[\varphi_{j}\right]$ & $\begin{array}{c}-0.123^{* *} \\
(0.026)\end{array}$ & $\begin{array}{c}-0.089^{* *} \\
(0.022)\end{array}$ & $\begin{array}{c}-0.0142^{\text {*** }} \\
(0.050)\end{array}$ & $\begin{array}{c}-0.077^{* * *} \\
(0.025)\end{array}$ \\
\hline $\ln R N D_{i, j, t-1}\left[\rho_{j}\right]$ & $\begin{array}{l}0.0058^{* *} \\
(0.000)\end{array}$ & $\begin{array}{l}0.0082^{* * *} \\
(0.000)\end{array}$ & $\begin{array}{l}0.0151^{* * *} \\
(0.006)\end{array}$ & $\begin{array}{l}0.0047^{*} \\
(0.003)\end{array}$ \\
\hline $\ln T R A_{i, j, t-1}\left[\pi_{1}\right]$ & $\begin{array}{l}0.0058^{*} \\
(0.002)\end{array}$ & $\begin{array}{l}0.0071^{*} \\
(0.003)\end{array}$ & $\begin{array}{l}0.0046^{\text {*** }} \\
(0.002)\end{array}$ & $\begin{array}{c}0.0036^{*} \\
(0.002)\end{array}$ \\
\hline $\ln I N T_{i, j, t-1}\left[\pi_{2}\right]$ & $\begin{array}{r}-0.0125 \\
(0.010)\end{array}$ & $\begin{array}{r}-0.0109 \\
(0.010)\end{array}$ & $\begin{array}{r}-0.0242 \\
(0.022)\end{array}$ & $\begin{array}{r}-0.0050 \\
(0.009)\end{array}$ \\
\hline $\ln T E R_{i, j, t-1}\left[\pi_{3}\right]$ & $\begin{array}{c}0.0051^{\dagger} \\
(0.003)\end{array}$ & $\begin{array}{l}0.0023^{*} \\
(0.001)\end{array}$ & $\begin{array}{l}0.01566 \\
(0.030)\end{array}$ & $\begin{array}{c}0.0018 \dagger \\
(0.001)\end{array}$ \\
\hline
\end{tabular}

Model 3: Regression with $\ln R N D_{i, j, t-1}$ replaced by $\ln P A T_{i, j, t-1}$

$\begin{array}{lcccc}\ln A_{i, j, t-1}\left[\varphi_{j}\right] & -0.1190^{* * *} & -0.0848^{* *} & -0.1410^{* *} & -0.0788^{* * *} \\ & (0.026) & (0.022) & (0.049) & (0.025) \\ \ln P A T_{i, j, t-1}\left[\rho_{j}\right] & 0.0143^{* * *} & 0.0046^{* *} & 0.0027^{* * *} & 0.026^{* *} \\ & (0.000) & (0.002) & (0.000) & (0.006) \\ \ln T R A_{i, j, t-1}\left[\pi_{1}\right] & 0.0106^{* * *} & 0.0043^{*} & 0.0104^{* *} & 0.0076^{*} \\ & (0.004) & (0.002) & (0.002) & (0.004) \\ \ln I N T_{i, j, t-1}\left[\pi_{2}\right] & -0.0070 & -0.0218 & -0.0058 & -0.0107 \\ & (0.060) & (0.015) & (0.042) & (0.011) \\ \ln T E R_{i, j, t-1}\left[\pi_{3}\right] & 0.0143^{*} & 0.0147^{*} & 0.0309 & 0.0040 \dagger \\ & (0.008) & (0.008) & (0.029) & (0.003)\end{array}$

Notes: Industry dummies are included in the pooled data set; values in parentheses are standard errors.

*Significant at 5\% level; ** significant at $1 \%$ level; †significant at $10 \%$ level.

(C) The London School of Economics and Political Science 2005 
R\&D efforts on TFP growth is strongest in COMP, weakest in ELEC and moderate in CHEM.

Model 2 conditions the convergence of TFP among firms on knowledge spillovers and internal knowledge flows by including three additional independent variables: $\ln T R A_{i, j, t-1}, \ln I N T_{i, j, t-1}$ and $\ln T E R_{i, j, t-1} \cdot{ }^{10}$ The estimated coefficients for $\ln A_{i, j, t-1}$ and $\ln R N D_{i, j, t-1}$ are robust to the addition of these variables. As in model 1, while the coefficient for $\ln A_{i, j, t-1}$ shows strong evidence for conditional convergence among firms in each of the three industries, the coefficients for $\ln R N D_{i, j, t-1}$ suggest that such convergence is positively related to R\&D efforts. The three rows at the bottom of Table 6 demonstrate the impact of knowledge spillovers on the convergence of TFP among firms. First, the estimated coefficients of $\ln T R A_{i, j, t-1}$ are positive and significant (at 5\% level) for all industries, which suggests that productivity laggards are able to grow faster by receiving knowledge spillovers from other firms operating in the same industry. Second, the estimated coefficients of $\ln I N T_{i, j, t-1}$ are not significant for all industries. One possible explanation is that 'self-learning', or 'firm-specific learning', is simply not an effective way for technology followers to catch up with the leaders. Another more plausible explanation is that an important share of self-learning efforts are reflected by R\&D intensities, as Table 1 suggests a significant correlation between these two variables. Finally, the estimated coefficient of $\ln T E R_{i, j, t-1}$ is significant for the sub-sample of CHEM (at 5\% level), marginally significant for ELEC (at 10\% level), and insignificant for COMP. Inter-industry spillovers are not therefore as strong as intra-industry spillovers in driving the convergence of TFP among firms.

While $R \& D$ expense is commonly treated as an input measure for $R \& D$ activities, patent count is a better measure for successful innovative output. Since patenting is a prerequisite for patent citations, the above results that patent citations increase productivity could therefore also reflect the impact of the firms' own patents as a measure of innovative output. A remedy for this potential bias is to include firm $i$ 's number of patents (i.e., $P A T_{i, j, t-1}$ ) in the regression equation. The estimated regression with $\ln P A T_{i, j, t-1}$ as an explanatory variable is specified as model 3 in Table 6. Owing to the high correlation between $P A T_{i, j, t}$ and $R N D_{i, j, t}$, as reported in Table $1, \ln R N D_{i, j, t-1}$ is excluded to avoid the problem of multicollinearity. Compared with model 2 , the estimated coefficients for $\ln A_{i, j, t-1}$ in model 3 are strongly robust to the use of $\ln P A T_{i, j, t-1}$ as a measure of $\mathrm{R} \& \mathrm{D}$ activities. The positive and strongly significant coefficients for $\ln P A T_{i, j, t-1}$ across all the sub-samples reaffirm the positive impact of R\&D efforts on TFP growth rate. Moreover, the use of $\ln P A T_{i, j, t-1}$ does not change fundamentally the sign and significance of the coefficients for intra-industry spillovers, inter-industry spillovers and internal knowledge flows.

As mentioned in Section I, the positive correlation between spillovers and R\&D spending may imply a conditional relationship between them. If this is the case, knowledge spillovers may not occur independently (as assumed implicitly in Table 6). The intensity of knowledge spillovers may indeed be conditional on $\mathrm{R} \& \mathrm{D}$ spending if the latter is taken as a measure of absorptive capacity of the receiving firms. The following TFP growth equation is specified to take into account the conditional relationship between knowledge spillovers

(C) The London School of Economics and Political Science 2005 
and absorptive capacity:

$$
\begin{aligned}
g_{i, j, t}^{A}= & \ln A_{i, j, t}-\ln A_{i, j, t-1}=\phi_{j}+\varphi_{j} \ln A_{i, j, t-1}+\rho_{j} \ln R N D_{i, j, t-1} \\
& +\pi_{1 j} \ln T R A_{i, j, t-1}+\pi_{2 j} \ln I N T_{i, j, t-1}+\pi_{3 j} \ln T E R_{i, j, t-1} \\
& +\varpi_{1 j} \ln T R A\left|R_{i, j, t-1}+\varpi_{2 j} \ln I N T\right| R_{i, j, t-1}+\varpi_{3 j} \ln T E R \mid R_{i, j, t-1}+\mu_{i, j, t}^{A},
\end{aligned}
$$

where $\ln T R A \mid R_{i, j, t-1}$ is the product of $\ln T R A_{i, j, t-1}$ and $\ln R N D_{i, j, t-1}$. $\ln I N T \mid R_{i, j, t-1}$ and $\ln T E R \mid R_{i, j, t-1}$ are defined similarly. The interaction terms in (8) imply that the impacts of intra-industry spillovers, inter-industry spillovers and internal knowledge flows on TFP depend on the absorptive capacity of the receiving firm (as measured by the firm's own R\&D). In other words, for any two firms having the same number of backward citations but different levels of $R \& D$, the one with a higher level of $R \& D$ can benefit more from knowledge spillovers and internal knowledge flows. ${ }^{11}$ The results of estimation are given in Table 7 (model 4). As shown in the table, the estimation of (8) results in a set of coefficients for $\ln A_{i, j, t-1}$ which is very similar to that of model 2 in Table 6 . The negative coefficients for $\ln A_{i, j, t-1}$ support the conditional convergence hypothesis. The strong impact of intra-industry spillovers on the convergence of TFP is again evidenced by the positive and significant coefficients for $\ln T R A_{i, j, t-1}$. More importantly, the positive and significant coefficients for $\ln T R A \mid R_{i, j, t-1}$ support the hypothesis that intraindustry spillovers are driving the convergence of TFP among firms, and that the strength of this driving force increases with the receiving firms' absorptive

TABLE 7

\begin{tabular}{|c|c|c|c|c|}
\hline Independent variable & Pooled sample & CHEM & COMP & ELEC \\
\hline \multicolumn{5}{|c|}{ Model 4: Regression with interaction terms } \\
\hline $\ln A_{i, j, t-1}$ & $\begin{array}{c}-0.125^{* *} \\
(0.027)\end{array}$ & $\begin{array}{c}-0.0932^{* * *} \\
(0.024)\end{array}$ & $\begin{array}{c}-0.136^{* * *} \\
(0.015)\end{array}$ & $\begin{array}{c}-0.0756^{*} \\
(0.029)\end{array}$ \\
\hline $\ln R N D_{i, j, t-1}$ & $\begin{array}{l}0.0187^{\text {*** }} \\
(0.006)\end{array}$ & $\begin{array}{l}0.0289^{* * *} \\
(0.003)\end{array}$ & $\begin{array}{l}0.0227^{\text {*** }} \\
(0.003)\end{array}$ & $\begin{array}{l}0.0170^{\text {*** }} \\
(0.005)\end{array}$ \\
\hline $\ln T R A_{i, j, t-1}$ & $\begin{array}{l}0.0166^{*} \\
(0.008)\end{array}$ & $\begin{array}{l}0.0148^{*} \\
(0.008)\end{array}$ & $\begin{array}{l}0.0186^{*} \\
(0.009)\end{array}$ & $\begin{array}{l}0.0085^{*} \\
(0.004)\end{array}$ \\
\hline $\ln I N T_{i, j, t-1}$ & $\begin{array}{r}-0.0362 \\
(0.036)\end{array}$ & $\begin{array}{r}-0.0191 \\
(0.054)\end{array}$ & $\begin{array}{r}-0.033 \\
(0.087)\end{array}$ & $\begin{array}{r}-0.0197 \\
(0.041)\end{array}$ \\
\hline $\ln T E R_{i, j, t-1}$ & $\begin{array}{l}0.0072 \dagger \\
(0.005)\end{array}$ & $\begin{array}{l}0.0032^{*} \\
(0.003)\end{array}$ & $\begin{array}{c}0.0082 \\
(0.007)\end{array}$ & $\begin{array}{l}0.0098 \dagger \\
(0.006)\end{array}$ \\
\hline $\ln T R A \mid R_{i, j, t-1}$ & $\begin{array}{l}0.0036^{*} \\
(0.002)\end{array}$ & $\begin{array}{l}0.0057^{*} \\
(0.003)\end{array}$ & $\begin{array}{l}0.0017^{*} \\
(0.000)\end{array}$ & $\begin{array}{c}0.0007^{*} \\
(0.000)\end{array}$ \\
\hline $\ln I N T \mid R_{i, j, t-1}$ & $\begin{array}{r}-0.0021 \\
(0.007)\end{array}$ & $\begin{array}{r}-0.0029 \\
(0.009)\end{array}$ & $\begin{array}{r}-0.0111 \\
(0.018)\end{array}$ & $\begin{array}{r}-0.0031 \\
(0.008)\end{array}$ \\
\hline $\ln T E R \mid R_{i, j, t-1}$ & $\begin{array}{l}0.0089 \dagger \\
(0.006)\end{array}$ & $\begin{array}{l}0.0097 \dagger \\
(0.006)\end{array}$ & $\begin{array}{l}0.0089^{*} \\
(0.004)\end{array}$ & $\begin{array}{r}0.0016 \\
(0.002)\end{array}$ \\
\hline
\end{tabular}

Pooled Cross-Section, Time Series Tests for Conditional Convergence of TFP $\left(\right.$ Dependent Variable $\left.=g_{i, j, t}^{A}\right)$

Notes: Industry dummies are included in the pooled data set; values in parentheses are standard errors.

*Significant at $5 \%$ level; ***ignificant at $1 \%$ level; $†$ significant at $10 \%$ level.

(C) The London School of Economics and Political Science 2005 
capacity. As in model 2, while the coefficients for inter-industry spillovers are marginally significant, the coefficients for internal knowledge flows are insignificant in model 4.

To summarize the empirical findings as shown in Tables 5, 6 and 7, evidence for conditional convergence is much stronger than that for absolute convergence. How might such differences emerge? First, the panel data tests (i.e. the pooled cross-section, time-series test) for conditional convergence allow each firm's TFP growth at time $t$ to respond to its level of TFP accomplished at time $t-1$. For instance, a firm with low TFP may experience rapid growth in accordance with the convergence hypothesis. To the extent that this firm closes the gap on high-TFP firms at time $t$, the convergence hypothesis implies that its growth rate should slow at time $t+1$. The panel data estimates facilitate such a scenario, whereas the cross-section tests for absolute convergence rule it out. Second, the panel data approach controls for firm-specific technological characteristics - R\&D efforts and knowledge spillovers. The findings for convergence may be associated with the view that technical know-how is a public good among firms. However, the ability of a firm to benefit from the public-good nature of knowledge depends on its absorptive capacity for receiving knowledge spillovers. For example, firms offering a wide range of products are able to derive a greater benefit from knowledge spillovers. ${ }^{12}$ Although all firms in an industry have equal exposure to a common pool of knowledge, the unequal scopes between them for receiving knowledge spillovers may cause the steady-state growth rate of TFP to vary across firms. The panel data approach for testing conditional convergence accommodates such differences across firms by allowing the steady state for each firm to be conditional on R\&D efforts and knowledge spillovers. As such, finding more evidence of convergence in the panel estimation appears reasonable. Importantly, if technology followers and leaders invest equally in $\mathrm{R} \& \mathrm{D}$ activities, the results of estimation predict that the followers will eventually catch up with the leaders, because the former tend to be the ones who receive knowledge spillovers from the latter.

\section{CONCLUSIONS}

With due reference to three high-tech industries, i.e. chemical (CHEM), computer (COMP) and electrical/electronic (ELEC), the primary objective of this study has been to evaluate the impacts of knowledge spillovers on the convergence of productivity among firms. The overall intensity of knowledge spillovers is measured by citation data in patent statistics. This measure is further decomposed into intra-industry spillovers, inter-industry spillovers and internal knowledge flows. Convergence of firms' productivity is tested in two ways: via a cross-section test for absolute convergence and a pooled crosssection, time series test for conditional convergence. The empirical findings suggest stronger evidence for conditional convergence than for absolute convergence. Specifically, with regard to conditional convergence, the results imply that each firm possesses its own steady-state growth rate of productivity, which is conditional on two major technological characteristics: R\&D efforts and intra-industry spillovers. In other words, a firm can grow faster, and 
accomplish a higher steady-state growth rate of productivity, either through $\mathrm{R} \& \mathrm{D}$ or through receiving knowledge spillovers from other firms operating in the same industry - or both. However, the actual intensity of knowledge spillovers received by a firm is limited by its absorptive capacity.

Comparison of productivity performance across firms is central to an important question in economics: are less productive firms catching up with the most productive ones, and if so how quickly and by what means? Both economists and business leaders express profound interest in whether the technology leader(s) of a particular industry (e.g. IBM in computers, Bayer and Dupont in chemicals and General Electric in the electrical and electronic industry) can maintain their role(s) as productivity leader(s). This study produces evidence for the positive relationship between knowledge spillovers and productivity convergence. Importantly, if technology followers and leaders share the same degree of R\&D intensity (although the empirical evidence from past studies shows that the leaders spend more on R\&D), the followers will eventually catch up with the leaders because the former tend to be the ones that receive knowledge spillovers from the latter. This finding is reasonable, as knowledge spillovers are extremely important to high-tech firms operating in a dynamic, fast changing market environment. In such an environment, with relatively short product life cycles, efficient spillovers of knowledge between firms allow them to make timely deliveries of innovations.

The empirical formulation employed by this study examines the impact of R\&D efforts and knowledge spillovers on productivity convergence without considering their possible interactions. For instance, the relationship between R\&D and spillovers could be either negative or positive, because they are not only alternative ways for firms to acquire knowledge, but are sometimes also complementary to one another. Moreover, as firms converge, knowledge spillovers among them are less likely to be a substitute for individuals' R\&D efforts. In addition, this study assumes that knowledge spillovers benefit the recipient only. In reality, however, knowledge spillovers may also benefit those firms giving out their technologies by generating network externalities. A typical example is the cooperative relationship between IBM and other manufacturers of IBM-compatible products. Further empirical research that takes these as-yet-untackled issues into account would be another valuable addition to the literature.

\section{ACKNOWLEDGMENTS}

The work described in this paper was supported by a Departmental Research Grant (GT266) at the Hong Kong Polytechnic University. I thank the two anonymous referees and colleagues at the Hong Kong University of Science and Technology (HKUST) for their thoughtful comments. I especially thank Professor William W. Chow of the Center for Economic Development at HKUST for his substantial efforts in data collection and computer programming. I am also grateful for the superb editing service offered by Professor Gillian Humphreys at the Department of English at the Hong Kong Polytechnic University.

\section{NOTES}

1. With the faster rate of technological progress and shorter product life cycles in today's economy, the time lags associated with knowledge diffusion tend to become shorter. 
2. Since patent citations delimit the scope of the property rights awarded by the patent, the applicant has a legal duty to disclose the previous knowledge (i.e. previous patents) on which the patent builds. Patent citations are supposed to be objective and informative, because the decision regarding which patents to cite ultimately rests with the patent examiners, who are experts in the area.

3. Instead of measuring knowledge spillovers directly by backward citations, Scherer constructs inter-industry technology flows matrices on the basis of input-output tables with $R \& D$ expenditures adjusted by a certain measure of technological proximity.

4. Following the suggestion of Griliches (1990), $t$ is the year of application for firm $i$ 's patents.

5. The sample includes the top-to-medium patenting firms in their respective industries. Within the sampling period, the number of patents granted to the top three patenting firms accounts for $29.6 \%, 43.4 \%$ and $36.3 \%$ of the total in CHEM, COMP and ELEC, respectively. The 224 firms in the sample account for less than $30 \%$ of the universe (all industries) because there is a large disparity between the top and the medium patenting firms.

6. It is possible that these values are upwardly biased owing to the narrowly defined industrial categories in the sample. The inter-industry knowledge pool is supposedly larger for a narrow definition of industrial categories. For instance, the computer industry is narrowly defined as comprising personal computers, large-scale computers, software and storage devices. Thus, a fairly large proportion of the knowledge spillovers shown in Table 1 could come from other closely related industries, such as semiconductors and computer electronics.

7. Two alternative generalizations of the Cobb-Douglas production function are the CES (constant elasticity of substitution) and the translog production functions, which have been used elsewhere in the literature on productivity comparisons. The limitations of these functions are discussed by Bernard and Jones (1996).

8. Attention is restricted to fixed effects because the random-effects model requires that the omitted variables be uncorrelated with the included independent variables, which is an unrealistic assumption in the context of this study.

9. A peculiar result in Table 2 is the evidence in favour of slightly decreasing returns to scale in CHEM, which is commonly used as an example of industries with significant economies of scale. The economies of scale are likely to be underestimated in this study by the exclusion of small firms from the sample. In addition, some studies (e.g. Hoffman and Kaplinsky 1990; Benson and Ponton 1993) suggest that the emergence of new technologies has reduced the optimal plant size in the chemical industry.

10. As pointed out by a referee, firm size may influence the rate at which firms converge to the steady state. However, firm size does not enter the regression here because $\ln A_{i, j, t}$ is actually the residual from the estimation of the production function (see equations (4) and (5)). Since physical capital and number of employees in the production function are common measures of firm size, $\ln A_{i, j, t}$ essentially represents the part of output growth that cannot be explained by these measures. I have tried to add $\ln K$ to the pooled sample as a size variable, but the estimated coefficient $(-0.054$; s.e. $=0.271)$ is not statistically significant as expected.

11. An alternative interpretation is that each unit of backward citation made by a firm with a higher level of $R \& D$ represents a larger amount of knowledge spillovers and internal knowledge flows.

12. As Klepper and Graddy (1990) mention, the best adopters of a technology are the users of that technology. Therefore, firms who have diverse experience in different disciplines tend to have a larger absorptive capacity for receiving knowledge spillovers.

\section{REFERENCES}

Aghion, P., Harris, C. and Vickers, J. (1995). Competition and growth with step-by-step technological progress. Mimeo.

BARRo, R. J. (1991). Economic growth in a cross section of countries. Quarterly Journal of Economics, 106, 407-43.

- and SAla-I-Martin, X. X. (1995). Economic Growth. New York: McGraw-Hill.

BAUMOL, W. J. (1986). Productivity growth, convergence and welfare: what the long-run data show. American Economic Review, 76, 1072-85.

Benson, R. and Ponton, J. W. (1993). Process miniaturization: a route to total environmental acceptability? Transactions of the Institute of Chemical Engineering, 71A, 160-8.

(C) The London School of Economics and Political Science 2005 
BERnARD, A. B. and Jones, C. I. (1996). Comparing apples to oranges: productivity convergence and measurement across industries and countries. American Economic Review, 86, 1216-38.

Blomstrom, M. (1989). Foreign Investment and Spillovers. London and New York: Routledge.

(1991). Host country benefits of foreign investment. NBER Working Paper no. 3615 .

— and Sлоноцм, F. (1998). Technology transfer and spillovers: does local participation with multinationals matter? European Economic Review, 43, 915-23.

Cockburn, I. M. and Henderson, R. M. (1994). Racing to invest? The dynamics of competition in ethical drug discovery. Journal of Economics and Management Strategy, 3, 481-519.

Friedman, M. (1992). Do old fallacies ever die? Journal of Economic Literature, 30, 2129-32.

FunG, M. K. and CHOw, W. W. (2002). Measuring the intensity of knowledge flow with patent statistics. Economics Letters, 74, 353-8.

Gilbert, R. J. and Newbery, D. M. G. (1982). Pre-emptive patenting and the persistence of monopoly. American Economic Review, 72, 514-26.

GRILICHES, Z. (1990). Patent statistics as economic indicators: a survey, part I. NBER Working Paper no. 3301

Hall, H. B., JafFe, B. A. and Trajtenberg, M. (2000). Market value and patent citations: a first look. NBER Working Paper no. 7741.

— - , and $\longrightarrow$ (2001). The NBER patent citations data file: lessons, insights, and methodological tools. NBER Working Paper no. 8498.

Hoffman, K. and Kaplinsky, R. (1990). Driving Force. London: Westview Press.

JAFFE, B. A. (1988). Demand and supply influences in R\&D intensity and productivity growth. Review of Economics and Statistics, 70, 431-37.

— - and HENDERSON, R. (1993). Geographic localization of spillovers as evidenced by patent citations. Quarterly Journal of Economics, 108, 577-98.

Jaffe, B. A., Trajtenberg, M. and Fogarty, M. (2000). Knowledge spillovers and patent citations: evidence from a survey of inventors. American Economic Review, 90, 215-18.

Jovanovic, B. and MacDonald, G. M. (1994). Competitive diffusion. Journal of Political Economy, 102, 24-52.

KLEPPER, S. and GRAdDY, E. (1990). The evolution of new industries and the determinants of market structure. RAND Journal of Economics, 21, 27-44.

LANJOUW, J. O. and SCHANKERMAN, M. (1999). The quality of ideas: measuring innovation with multiple indicators. NBER Working Paper no. 7345.

LiU, X., Siler, P., WANG, C. and Wei, Y (2000). Productivity spillovers from foreign direct investment: evidence from UK industry level panel data. Journal of International Business Studies, 31, 407-25.

LiU, Z. (2002). Foreign direct investment and technology spillover: evidence from China. Journal of Comparative Economics, 30, 579-602.

Mankiw, N. G., Romer, D. and Weil, D. N. (1992). A contribution to the empirics of economic growth. Quarterly Journal of Economic, 107, 407-37.

Mansfield, E., Schwartz, M. and Wagner, S. (1981). Imitation costs and patents: an empirical study. Economic Journal, 91, 907-18.

Nabseth, L. and RAy, G. (1974). The Diffusion of New Industrial Processes: An International Study. Cambridge: Cambridge University Press.

NADIRI, M. I. (1993). Innovations and technological spillovers. NBER Working Paper no. 4423.

QUAH, D. (1993). Galton's fallacy and tests of the convergence hypothesis. Scandinavian Journal of Economics, 95, 427-43.

REINGANUM, J. F. (1989). The timing of innovation: research, development, and diffusion. In R. Schmalensee and R. D. Willig (eds.), Handbook of Industrial Organization. New York: NorthHolland.

Rogers, E. M. (1983). Diffusion of Innovations, 3rd edn. New York: Free Press.

SAla-I-MARTin, X. X. (1996). The classical approach to convergence analysis. Economic Journal, 106, 1019-36. 
SCHERER, F. M. (1981). Using linked patent and R\&D data to measure inter-industry technology flows. In Z. Griliches (ed.), $R \& D$, Patents and Productivity. Chicago: University of Chicago Press for NBER, pp. 417-64.

SPENCE, M. (1984). Cost reduction, competition and industry performance. Econometrica, 52, $101-21$.

VON DER FeHR, N. H. M. (1993). Entry-inducing technology adoption. Economics Letters, 42 , $269-73$. 